\title{
Changes in Abdominal Muscle Thickness and Balance Ability on Plank Exercises with Various Surfaces
}

\author{
Kyung-Woo Kang', Sung-Min Son², Yu-Min Ko
}

'Department of Physical Therapy, College of Health and Therapy, Daegu Haany University, Daegu; ${ }^{2}$ Department of Physical Therapy, College of Health Science, Cheongju University, Cheongju; ${ }^{3}$ Department of Physical Therapy, Gangneung Yeongdong College, Gangneung, Korea

Purpose: This study was conducted to investigate the effects on muscle thickness and balance ability after performing plank exercise on various surface types.

Methods: In this study, there were thirty healthy participants. Participants were randomly distributed into three groups, a control group $(n=10)$, sling group $(n=10)$, and ball group $(n=10)$. All participants performed plank exercises three times a week for four weeks. Plank exercises consisted of five sets of 30 seconds each with a one minute break between each set. Muscle thickness of the transverse abdominis (TrA), internal oblique (IO), and external oblique (EO) was measured using an ultrasound diagnostic apparatus and balance was measured using I-balance.

Results: Evaluation of muscle thickness revealed that the $\mathrm{IO}$ and $\mathrm{EO}$ muscle of the ball group changed significantly relative to the control group $(p<0.05)$. However, there were no significant changes in balance.

Conclusion: The results revealed that performing plank exercise on a ball is more effective among various types of surfaces.

Keywords: Plank exercise, Swiss ball, Sling, Muscle thickness, Balance

\section{서 론}

플랭크(plank) 동작은 코어(core) 안정성을 검사하는 방법 중 하나 이며 동시에 코어 안정성을 증진시키는 운동 중 하나로 널리 사용되 고 있다. 플랭크 동작이란 엎드린 교각 자세로 아래팔과 양 발을 이 용해서 몸을 지탱하는 동작이고, 코어란 척추 기둥에 안정성을 제공 하는 골반과 체간 주위의 근육 구조물로 설명된다. 플랭크 동작 등 으로 단련될 수 있는 코어 근육군 중 특히 배부위 근육의 근력 및 지 구력은 스포츠 활동을 하는 동안 신체의 움직임을 향상시키기 위해 중요한 요소로 알려져 있다. ${ }^{34}$ 그 밖에 플랭크 동작을 통한 코어 근육 의 강화는 허리 손상의 발생을 줄일 수 있고, 운동 수행능력을 증진 시킬 수 있다. 특히, 최근 전통적인 윗몸 일으키기 방식 훈련을 통해 반복적으로 체간을 구부리게 되면 추간판 디스크의 손상을 일으킬 수 있다는 연구가 보고 되면서 코어 근육을 강화시키기 위한 동작으 로 플랭크 동작이 더욱 일반화되고 있다. ${ }^{6}$

코어의 강화는 대표적으로 허리 통증의 예방 및 치료에 효과가 있
고 운동 수행능력을 향상 시킬 수 있다고 알려져 있지만 그 밖에도 등속성 근력 증가, 허리 유연성 증가, 균형능력의 증가 등에도 효과가 있다고 보고되고 있다.7.8 이 중 균형 능력은 낙상과 매우 밀접한 연관 이 있는 요소로 알려져 있는데, 최근에는 노인뿐만 아니라 젊은 성인 들도 다양한 스포츠 활동으로 낙상을 경험하고 이로 인한 부상을 겪 고 있다.9 이러한 균형 능력을 잘 유지하기 위해서는 감각시스템 뿐 아 니라 외부 환경에 대한 신체적 안정성과 긴장성을 조절하는 것이 필 요한데 코어의 강화와 같은 근육 향상 훈련이 이를 도울 수 있다. ${ }^{10}$

최근 들어, 이러한 플랭크 동작의 효과를 극대화하기 위해 다양한 형태로 응용되는 방식에 대한 연구가 이뤄지고 있다.1112 체간을 지지 하는 어깨관절의 각도를 다양화 하거나 아래팔 이나 양발 아래에 불 안정면을 두는 조건, 또는 사이드 플랭크나 스위스볼(swiss ball) 등의 도구를 이용하는 등의 방식들과 같이 다양한 방법들을 시도하여 더 좋은 효과를 내는 동작을 찾는 연구들이 보고되고 있다.11-13 이 중 스 위스 볼이나 서스펜션(천장에 매달린 줄의 손잡이를 잡고 하는 운 동)과 같이 불안정한 지지면을 제공하는 도구를 활용하는 방법에 대 
한 연구가 최근 들어 활발히 이뤄지고 있다. ${ }^{2}$ 이러한 연구들에서는 플 랭크 동작의 효과를 알아보기 위해 주로 근전도를 사용하고 있지만, 최근에는 영상진단 장비의 발전에 따라 비침습적이고 안전하며 골격 근의 특징을 잘 평가할 수 있는 초음파 장비가 널리 활용되고 있다. 특히 심부 근육과 같이 근육의 작용을 측정하기 어려울 때에 초음파 는 더욱 효과적이다. ${ }^{14}$

이전까지 플랭크를 통한 코어 근육 강화의 효과를 알아보는 선행 연구는 있었지만, 지지면의 형태에 따른 플랭크 운동이 근육두께의 변화에 영향을 미치는지, 나아가서는 이러한 코어의 변화가 균형 능 력에도 영향을 끼치는지에 대해 조사한 연구는 많지 않았다. 따라서 본 연구에서는 플랭크 운동을 다양한 지지면에서 4주간 훈련시켰을 때의 배가로근과 배속빗근 및 배바깥빗근의 두께 변화와 균형 능력 의 변화를 조사하여 좀 더 효과적인 플랭크 운동방법을 제시하고자 하고자 한다.

\section{연구방법}

\section{1. 연구대상}

본 연구의 대상자는 C대학교에 재학 중인 건강한 20-30대 남녀 30 명을 대상으로 실시하였다. 모든 대상자는 실험 전에 본 연구에 대한 목적과 운동방법에 대한 설명을 듣고 자발적으로 실험에 동의하였으 며, 연구 참여 동의서에 서명하였다. 대상자들은 플랭크 훈련을 실시 하는 지면의 형태에 따라 무작위 선정을 통해 세 그룹으로 나누었다. 대상자 선별 기준은 실험에 영향을 줄 수 있는 신체적 결함과 균형에 영향을 줄 수 있는 신경학적 결함이 없는 자로 선정하였으며, 최근 3 개월간 허리통증을 경험자, 심각한 자세 기형이 있는 자 혹은 실험 결 과에 영향을 줄 수 있는 체계적인 운동을 하고 있는 자는 연구에서 제외하였다.

\section{2. 실험방법}

\section{1) 실험절차}

본 연구는 다양한 지면의 형태에 따라 일반적인 플랭크훈련 그룹 $(\mathrm{n}=10)$, 슬링을 이용한 플랭크훈련 그룹 $(\mathrm{n}=10)$ 과 스위스 볼을 이용 한 플랭크훈련 그룹 $(\mathrm{n}=10)$ 으로 분류하였다. 세 그룹은 무작위 배정 으로 분류하였다. 일반적인 플랭크훈련 그룹의 자세는 elbow-toe 자 세를 기본으로 하였다. Elbow-toe 자세는 엎드려 양팔을 어깨너비로 벌리고 어깨와 팔꿈치가 수직이 되도록 만든 뒤 무릎 폄과 함께 발끝 으로 자세를 유지하도록 한 자세이다. 또한 대상자들에게 가능한 머 리, 등과 다리가 일직선을 유지하도록 지시하였다. 슬링 플랭크훈련 그룹과 스위스 볼 플랭크훈련 그룹은 일반적인 플랭크 운동자세에서 하지쪽 지지면의 불안정성을 유도하기 위해 슬링과 스위스 볼을 이
용하였다. 슬링의 높이와 스위스 볼의 크기는 머리에서 발뒤꿈치까지 수평을 유지할 수 있는 높이로 설정하였다. 플랭크 운동은 세 그룹 모 두 주 3 회 4 주간 훈련을 실시하였고, 적용시간은 1 일 5 세트(30초 운동 과 1 분 휴식을 1 세트)로 하였다.

\section{2) 측정도구 및 측정방법}

훈련 전·후 배가로근과 배속빗근 및 배바깥빗근의 근육 두께의 변 화를 측정하기 위해 초음파 영상장치(Mysono U6, Apexium Medical Group Inc., France)를 이용하였다. 각 근육의 단면에서 근막을 제외한 두께를 길이로 측정하였다. 측정은 바로 누운 자세에서 무릎을 $45^{\circ}$ 정도 굽힌 자세에서 초음파를 측정하였다. 배가로근, 배속빗근과 배 바깥빗근의 초음파 측정 위치는 겨드랑이 선에서 몸통 바깥쪽으로 아래로 그은 선과 배꼽의 가로 선이 교차하는 지점에서 앞쪽 $2.5 \mathrm{~cm}$ 부위에서 측정하였다. ${ }^{5}$ 모든 측정은 왼쪽과 오른쪽을 측정한 후 양 쪽 근육 두께의 평균을 값으로 취하였다. 측정 시 호흡에 따른 변화 를 최소화하기 위해서 이완된 날숨 끝에서 측정하였고, 검사자 간의 측정 차이를 최소화하기 위해 동일한 검사자가 실시하였으며, 오차 범위를 줄이기 위해 3 회 측정 후 평균값을 사용하였다.

훈련 전·후 선 자세에서 동적 균형능력을 평가하기 위해 힘판(forceplate) 기반의 자세균형 시스템(IBalance, Cybermedic Co., Korea)를 사용하였다. 이 장비는4개의 로드셀(loadcell)이 장착된 $600 \times 400$ 크 기의 힘판을 이용하여 신체동요에 따른 압력중심(center of press)의 변화를 측정할 수 있도록 설계되었고, 자세 안정성을 유지하는 동안 동요 속도와 이동거리를 측정하여 균형 능력을 평가 할 수 있는 장비 이다. 동적 균형능력을 평가하기 위해 대상자는 힘판 위에 설치된 스 폰지 위에서 눈을 뜬 상태와 눈을 감은 상태로 측정하였고, 각 자세 에서 10 초간 균형 능력을 측정하였다. 대상자에게 측정방법 및 절차 를 설명하고 1 회의 연습기간이 주어졌으며, 자료는 3 회 측정하여 얻 은 결과값의 평균값을 산출하였다.

\section{3. 통계분석}

세 그룹 간의 나이, 키, 몸무게는 일요인 분산분석(one-way ANO$\mathrm{VA}$ )를 사용하여 비교하였다. 플랭크 훈련 방법에 따른 근육 두께와 균형 능력에 미치는 효과를 비교하기 위해 이요인 반복측정 분산분 석(two-way repeated measure ANOVA)을 사용하였고, 집단 간 비교를 위해 사후 검정(Bonferroni correction)을 실시하였다. 수집 된 측정 값 들의 통계분석은 SPSS version 12.0 (SPSS Inc., Chicago, IL, USA) 프로 그램을 이용하였고, 통계학적 유의 수준을 검정하기 위하여 $p<0.05$ 로 설정하였다. 


\section{결 과}

\section{1. 연구대상자의 일반적 특성}

연구 대상자의 일반적 특성은 Table 1과 같다. 세 그룹 사이의 성별, 나이, 몸무게와 키에서 유의한 차이가 없었다 $(\mathrm{p}>0.05)$.

Table 1. The general characteristics of subjects

\begin{tabular}{lccc}
\hline & $\begin{array}{c}\text { Control group } \\
(n=10)\end{array}$ & $\begin{array}{c}\text { Sling group } \\
(n=10)\end{array}$ & $\begin{array}{c}\text { Ball group } \\
(n=10)\end{array}$ \\
\hline Gender (male/female) & $8 / 2$ & $8 / 2$ & $8 / 2$ \\
Age (year) & $23.20 \pm 1.32$ & $22.10 \pm 0.99$ & $20.30 \pm 0.48$ \\
Weight $(\mathrm{kg})$ & $65.60 \pm 11.82$ & $63.70 \pm 8.59$ & $61.50 \pm 6.31$ \\
Height $(\mathrm{cm})$ & $172.30 \pm 8.39$ & $171.30 \pm 5.38$ & $170.30 \pm 8.80$ \\
\hline
\end{tabular}

Mean \pm S.D.

\section{2. 세 그룹의 중재 전·후 배가로근, 배속빗근, 배바깥빗근의 두께 변화비교}

중재 전. 후 배가로근, 배속빗근 및 배바깥빗근의 두께를 비교한 결 과 집단 내에서 유의한 증가를 보였다 $(\mathrm{p}<0.05)$. 배가로근의 두께에서 는 중재방법과 측정시점의 교호작용에서 유의한 차이를 보이지 않았 다 $(\mathrm{F}=1.33, \mathrm{p}>0.05)$. 하지만, 배속빗근과 배바깥빗근의 두께는 중재방 법과 측정시점에서 교호작용에서는 유의한 차이를 보였다 $(\mathrm{F}=4.14$, $\mathrm{F}=3.85, \mathrm{p}<0.05)$. 배속빗근과 배바깥빗근의 두께 변화에 대한 사후 검 정 결과 스위스 볼 플랭크 훈련 그룹이 일반 플랭크 훈련 그룹보다 유 의한 근육 두께의 증가를 보였다 $(\mathrm{p}<0.05)$ (Table 2).

\section{3. 세 그룹의 중재 전·후 동적균형능력 비교}

중재 전. 후 눈을 뜬 상태와 눈을 감은 상태에서 동요속도와 동요

Table 2. Comparison of muscle thickness between the three groups

\begin{tabular}{|c|c|c|c|c|c|c|}
\hline \multicolumn{2}{|c|}{ Muscle thickness (mm) } & \multirow{2}{*}{$\begin{array}{c}\text { Control group }(n=10) \\
2.96 \pm 0.81\end{array}$} & \multirow{2}{*}{$\begin{array}{c}\text { Sling group }(n=10) \\
3.02 \pm 0.61\end{array}$} & \multirow{2}{*}{$\begin{array}{c}\text { Ball group }(n=10) \\
2.74 \pm 0.57\end{array}$} & \multicolumn{2}{|c|}{$\mathrm{F}$} \\
\hline \multirow[t]{4}{*}{$\operatorname{Tr} A$} & Pre-test & & & & Group & 0.16 \\
\hline & Post-test & $3.07 \pm 0.62$ & $3.18 \pm 0.49$ & $3.21 \pm 0.63$ & Time & $6.14^{*}$ \\
\hline & & & & & Group $\times$ Time & 1.33 \\
\hline & Change value & $0.11 \pm 0.56$ & $0.16 \pm 0.40$ & $0.47 \pm 0.71$ & & \\
\hline \multirow[t]{4}{*}{10} & Pre-test & $7.28 \pm 1.70$ & $7.46 \pm 1.60$ & $7.14 \pm 1.21$ & Group & 0.12 \\
\hline & Post-test & $7.93 \pm 1.30$ & $8.06 \pm 1.59$ & $8.66 \pm 1.34$ & Time & $38.65^{\star}$ \\
\hline & & & & & Group $\times$ Time & $4.14^{*}$ \\
\hline & Change value & $0.65 \pm 0.79$ & $0.60 \pm 0.80$ & $1.52 \pm 0.95^{+}$ & & \\
\hline \multirow[t]{4}{*}{ EO } & Pre-test & $4.06 \pm 1.18$ & $4.00 \pm 1.02$ & $3.88 \pm 1.14$ & Group & 0.54 \\
\hline & Post-test & $4.90 \pm 0.90$ & $5.18 \pm 1.29$ & $5.95 \pm 1.42$ & Time & $54.32^{*}$ \\
\hline & & & & & Group $\times$ Time & $3.85^{\star}$ \\
\hline & Change value & $0.86 \pm 1.22$ & $1.18 \pm 0.81$ & $2.06 \pm 1.11^{+}$ & & \\
\hline
\end{tabular}

${ }^{*} \mathrm{p}<0.05 ;$ ' Significant difference with control group.

TrA: transverse abdominis, IO: internal oblique, EO: external oblique.

Table 3. Comparison of dynamic balance ability between the three groups

\begin{tabular}{|c|c|c|c|c|c|c|c|}
\hline \multicolumn{3}{|l|}{ Balance } & \multirow{2}{*}{$\frac{\text { Control group }(n=10)}{2.48 \pm 0.68}$} & \multirow{2}{*}{$\frac{\text { Sling group }(n=10)}{2.29 \pm 0.55}$} & \multirow{2}{*}{$\frac{\text { Ball group }(n=10)}{2.43 \pm 0.47}$} & \multicolumn{2}{|c|}{$\mathrm{F}$} \\
\hline \multirow[t]{8}{*}{ Eye open } & Velocity $(\mathrm{cm} / \mathrm{s})$ & Pre-test & & & & Group & 0.67 \\
\hline & & Post-test & $2.23 \pm 0.56$ & $2.02 \pm 0.59$ & $2.10 \pm 0.59$ & Time & $12.43^{*}$ \\
\hline & & & & & & Group $\times$ Time & 0.08 \\
\hline & & Change value & $-0.25 \pm 0.28$ & $-0.27 \pm 0.52$ & $-0.33 \pm 0.56$ & & \\
\hline & Distance $(\mathrm{cm})$ & Pre-test & $44.20 \pm 9.25$ & $41.37 \pm 8.61$ & $43.25 \pm 8.33$ & Group & 0.51 \\
\hline & & Post-test & $40.53 \pm 7.13$ & $36.79 \pm 6.71$ & $37.19 \pm 8.49$ & Time & $30.59^{\star}$ \\
\hline & & & & & & Group $\times$ Time & 0.65 \\
\hline & & Change value & $-3.67 \pm 3.15$ & $-4.58 \pm 3.97$ & $-6.05 \pm 6.92$ & & \\
\hline \multirow[t]{8}{*}{ Eye close } & Velocity (cm/s) & Pre-test & $3.53 \pm 1.02$ & $3.79 \pm 1.04$ & $3.89 \pm 1.15$ & Group & 4.47 \\
\hline & & Post-test & $3.35 \pm 1.16$ & $3.55 \pm 1.17$ & $3.56 \pm 1.08$ & Time & $0.28^{*}$ \\
\hline & & & & & & Group $\times$ Time & 0.15 \\
\hline & & Change value & $-0.18 \pm 0.62$ & $-0.25 \pm 0.85$ & $-0.33 \pm 0.57$ & & \\
\hline & Distance $(\mathrm{cm})$ & Pre-test & $61.86 \pm 14.60$ & $63.79 \pm 14.93$ & $64.91 \pm 12.50$ & Group & 0.09 \\
\hline & & Post-test & $60.47 \pm 15.18$ & $62.03 \pm 14.70$ & $62.33 \pm 12.62$ & Time & $4.73^{*}$ \\
\hline & & & & & & Group $\times$ Time & 0.16 \\
\hline & & Change value & $-1.39 \pm 5.02$ & $-1.76 \pm 5.97$ & $-2.58 \pm 3.95$ & & \\
\hline
\end{tabular}

${ }^{*} p<0.05$. 
거리 비교한 결과 집단 내에서 모두 유의한 감소를 보였다 $(\mathrm{p}<0.05)$. 하지만, 중재방법과 측정시점의 교호작용에서는 모두 유의한 차이를 보이지 않았다 $(\mathrm{F}=0.08, \mathrm{~F}=0.65, \mathrm{~F}=0.15, \mathrm{~F}=0.16, \mathrm{p}>0.05$ ) (Table 3).

\section{고 찰}

본 연구에서는 코어 강화 훈련 중 하나인 플랭크 동작을 실시하는 동안, 발에 대한 지지면을 지면, 슬링, 스위스볼로 각각 다르게 제공했 을 때의 배가로근과 배속빗근 및 배바깥빗근의 두께 변화와 균형 능 력의 변화가 어떻게 나타나는 지에 대해 조사하였다. 그 결과 스위스 볼 플랭크 훈련 그룹의 배속빗근과 배바깥빗근이 일반 플랭크 훈련 그룹보다 유의한 두께의 향상을 보였다. 균형 능력에서는 통계학적으 로는 그룹 간 유의미한 차이를 보이지 못했다.

스위스 볼과 슬링은 모두 플랭크를 위한 좋은 도구이며, 슬링을 사 용하는 것은 비록 유의미한 결과를 나타내지는 못했지만 일반적인 플랭크에 비해서는 좋은 효과를 나타냈다. 한 선행 연구에 따르면 코 어를 강화하는 여러가지 운동 방법 중 서스펜션과 같이 불안정면 위 에서 플랭크 훈련하였을 때, 배가로근과 배속빗근 및 배바깥빗근의 두께 변화가 유의하게 증가하였다고 보고하였으며, 이때 배바깥빗근 의 복부근육 두께의 변화는 배가로근과 배속빗근보다 더 컸다고 보 고하였다. ${ }^{16}$ 이는 슬링이나 스위스볼과 같이 불안정면 위에서 플랭크 훈련을 하는 것이 일반적인 플랭크 훈련보다 좋은 효과를 낼 수 있다 는 것을 의미한다.

스위스 볼을 이용하는 운동은 신체가 불안정한 면 위에서 계속해 서 균형을 잡으려고 시도하게 하여 신체의 각 분절의 동원이 동시에 발현되도록 하는 특징을 가지고 있다. 이러한 동시적 신체 동원은 고 유수용기의 자극과 코어를 포함한 신체 각 부위의 균등한 근육의 향 상을 가져올 수 있다. ${ }^{17}$ 슬링 또한 매달려 있는 줄을 이용하여 불안정 한 면을 제공하는 운동으로 신체적으로 쇠약한 환자부터 운동선수 까지 적용 스펙트럼이 매우 넓은 장점을 가지고 있고, ${ }^{18}$ 불안정한 면 을 제공함으로써 신경근육계를 자극하여 근육의 동시수축을 증가 시키고 동시에 감각운동훈련도 가능하게 한다. ${ }^{19}$ 본 연구 결과에 비춰 보았을 때 스위스 볼을 이용하는 운동은 슬링을 이용하는 것에 비해 서는 신체 균형 유지를 위해 좀 더 높은 수준의 근 수축을 유도하는 것으로 생각된다.

일부 선행 연구가 이를 뒷받침 하는데 한 연구에서는 일반적 플랭 크와 상지와 하지에 각각 밸런스 패드를 불안정면으로 제공한 플랭 크 훈련에서 코어 근육의 두께를 초음파를 이용하여 측정한 결과, 하 지에 불안정면을 제공한 그룹에서 배가로근과 배속빗근의 근육 두께 가 가장 크게 변화한다고 보고하였다. ${ }^{2}$ 그리고 지면 유형 별 플랭크 운동 시 코어 근육의 활성도가 안정된 면보다 스위스 볼 위에서 실시
될 때 더욱 증가된다고 보고된 연구가 있었는데, ${ }^{20}$ 이러한 결과는 슬 링보다는 스위스 볼과 같이 공기를 주입한 형태의 도구가 좀 더 강한 복부 근육의 수축을 요구한다는 것을 의미한다. 이는 플랭크 동작 동 안의 신체 균형 유지와 밀접한 연관이 있을 것으로 생각된다.

한편, 스위스 볼 운동은 관절가동범위를 유지 또는 증가 시키는데 효과적이며, 유연성 및 균형 등 다양한 운동 효과를 가진다고 보고되 고 있다. ${ }^{21}$ 이 중 균형 능력의 향상을 알아보기 위한 코어 강화 훈련과 관련된 선행 연구가 있었다. 한 연구에서는 유소년 축구선수 30 명을 대상으로 코어 안정화 운동을 실시하여 균형능력의 변화를 비교한 결과 코어 운동군의 균형능력이 허리 등장성 운동군이나 대조군에 비해 유의하게 증가하였다고 보고하였다. 또 다른 연구에서는 국가 대표 리듬체조 선수들을 대상으로 8주간 코어 강화 운동 후 균형능 력의 운동 전후를 비교한 결과 균형능력의 향상이 나타났다고도 보 고하였다.

적절한 코어 조절능력의 상실은 척추 기둥의 불안정성의 결과를 가져오고 신체의 동적 균형을 유지하기 위한 능력의 감소를 가져온 다. ${ }^{22}$ 그러나 본 연구에서는 스위스 볼 훈련 그룹이나 슬링 훈련 그룹 에서 균형능력의 향상은 나타났으나 통계학적으로 유의미함을 보이 진 못했다. 한 선행 연구에서는 필라테스 운동과 같은 코어 강화 훈련 은 정상 범위의 균형능력을 가진 사람도 균형을 향상 시킬 수 있지만 일반적으로 향상의 범위가 작을 수 있다고 보고했고, 이러한 작은 변 화는 운동 선수들에게는 운동 수행 능력에 향상을 가져 올 수 있을 정도이지만 일상생활을 하는 건강한 성인들에게는 영향이 없을 지 도 모른다고 보고하였다. ${ }^{23}$

본 연구의 결과로 플랭크 동작 시 하지에 스위스 볼, 슬링을 추가 응용하면 복부 근육이나 균형능력에 향상을 가져 온다는 사실을 알 수 있었다. 이를 통해 임상에서 코어 근육의 강화나 균형능력의 향상 이 필요한 환자들이 있다면 플랭크 동작을 적용함에 있어 좋은 참고 자료로 이용될 수 있을 것이라 생각된다. 본 연구에는 몇 가지 제한점 이 있다. 첫째로, 실험기간의 4 주로 그렇게 길지 않았다는 점이 있다. 둘째는, 코어 근육이 심각하게 약하지 않는 젊은 층을 대상자로 한정 한 점이다. 따라서 추후 연구에서는 플랭크 동작을 다양한 대상자 군 에 적용할 필요성이 있다고 생각된다. 최근에는 생활 습관에 따른 요 통 환자가 급증하고 있으므로 요통 환자 군에게 코어 강화 훈련을 적 용하거나, 많은 동작을 수행하는 운동선수에게 적용하였을 때의 효 과도 알아볼 필요가 있을 것이다. 본 연구에서 좀 더 효과적인 코어 훈련으로 인식된 스위스 볼을 이용한 플랭크 훈련이, 향후 연구에서 는 다양한 대상자 군에 적용하여 얼마나 효용성이 있을지에 대해 조 사한다면 우리 사회의 개개인들의 삶의 질을 향상시키는 데에 높은 기여를 할 수 있을 것으로 기대된다. 


\section{참고문헌}

1. Do YC, Yoo WG. Comparison of the thicknesses of the transversus abdominis and internal abdominal obliques during plank exercises on different support surfaces. J Phys Ther Sci. 2015;27(1):169-70.

2. Snarr RL, Esco MR. Electromyographical comparison of plank variations performed with and without instability devices. J Strength Cond Res. 2014;28(11):3298-305.

3. Cosio-Lima LM, Reynolds KL, Winter C et al. Effects of physioball and conventional floor exercises on early phase adaptations in back and abdominal core stability and balance in women. I Strength Cond Res. 2003; 17(4):721-5.

4. Yoon MR, Choi HS, Shin WS. Effects of the abdominal drawing-in maneuver and the abdominal expansion maneuver on grip strength, balance and pulmonary function in stroke patients. J Kor Phys Ther. 2015;27(3): 147-53.

5. Duncan M. Muscle activity of the upper and lower rectus abdominis during exercises performed on and off a swiss ball. J Bodyw Mov Ther. 2009; 13(4):364-7.

6. Tampier C, Drake JD, Callaghan JP et al. Progressive disc herniation: an investigation of the mechanism using radiologic, histochemical, and microscopic dissection techniques on a porcine model. Spine (Phila Pa 1976). 2007;32(25):2869-74.

7. Cho YH. Effect of isotonic exercise program and core exercise program on isokinetic muscular strength, flexibility, balance, and visual analog scale of teenage soccer player. Kyunghee University. Dissertation of Master's Degree. 2010.

8. Kwon BY. Effects of core stability and mobility training with aero equipment on biomechanical balance, posture, strength and agility for rhythmic gymnasts. Ewha Womans University. Dissertation of Doctorate Degree. 2008

9. Kim MH, Kim YS, Yoon BC. Gender difference in trunk stability and standing balance during unexpected support surface translation in healthy adults. J Kor Phys Ther. 2014;26(2):97-103.

10. Lim JH, Park JS, Cho WS. Cerebral infarction, dynamic balance, mechanical horseback riding. J Kor Phys Ther. 2014;26(2):123-9.
11. Hwang JH. Comparsion trunk muscle activation according to shoulder angle by plank exercise. Catholic University of Daegu. Dissertation of Master's Degree. 2014.

12. Do YC. A comparison of different type of surface during plank exercise on transversus abdominis and internal obliques thickness using an ultrasound imaging. Inje University. Dissertation of Master's Degree. 2014.

13. Shin YA. Comparison of core stabilizer muscle activity according to movement difficulty and stability during various trx plank. The Official Journal of the Korean Academy of Kinesiology. 2014;16(4):31-41.

14. Lee JA, Kim SY. Reliability of ultrasonography for the longus colli in asymptomatic subjects. J Kor Phys Ther. 2011;23(4):59-66.

15. Critchley DJ, Coutts FJ. Abdominal muscle function in chronic low back pain patients: measurement with real-time ultrasound scanning. Physiotherapy. 2002;88(6):322-32.

16. Mok NW, Yeung EW, Cho JC et al. Core muscle activity during suspension exercises. J Sci Med Sport. 2015;18(2):189-94.

17. Han SW, Lee DJ, Lee ES. Effects of trunk muscle strength, coordination and pain after sling and swiss ball exercise for low back pain patients Journal of Coaching Development. 2014;16(3):123-32.

18. Kang H, Jung J, Yu J. Comparison of trunk muscle activity during bridging exercises using a sling in patients with low back pain. J Sports Sci Med. 2012;11(3):510-5.

19. Verbunt JA, Seelen HA, Vlaeyen JW et al. Disuse and deconditioning in chronic low back pain: concepts and hypotheses on contributing mechanisms. Eur J Pain. 2003;7(1):9-21.

20. Behm DG, Anderson K, Curnew RS. Muscle force and activation under stable and unstable conditions. J Strength Cond Res. 2002;16(3):416-22.

21. Lee SC. The effect of 12 week swiss ball exercise on physical fitness and balance in the elderly. Kookmin University. Dissertation of Master's Degree. 2008 .

22. Stokes IA, Gardner-Morse M, Henry SM et al. Decrease in trunk muscular response to perturbation with preactivation of lumbar spinal musculature. Spine (Phila Pa 1976). 2000;25(15):1957-64.

23. Eric GJ, Andrea L, Hiromi $\mathrm{O}$ et al. The effects of pilates-based exercise on dynamic balance in healthy adults. J Bodyw Mov Ther. 2007;11(3): $239-42$. 